\title{
ANALISIS MULTIDIMENSIONAL UNTUK PENGELOLAAN PERIZINAN PERIKANAN YANG BERKELANJUTAN : STUDI KASUS WPP LAUT ARAFURA
}

\author{
(MULTIDIMENSIONAL ANALYSIS OF CAPTURE FISHERIES BUSINESS \\ LICENSING MANAGEMENT : CASE STUDY OF ARAFURA SEA)
}

\author{
Ridwan Mulyana ${ }^{12}$, John Haluan ${ }^{3}$, Mulyono S. Baskoro ${ }^{3}$ dan Sugeng Hari Wisudo ${ }^{3}$ \\ ${ }^{1}$ Corresponding author \\ ${ }^{2}$ Direktorat Jenderal Perikanan Tangkap, Kementerian Perikanan dan Kelautan \\ E-mail : ridwan_mulyana99@yahoo.com \\ ${ }^{3}$ Departemen Pemanfaatan Sumberdaya Perikanan \\ Fakultas Perikanan dan Ilmu Kelautan IPB
}

\begin{abstract}
Fishing license, as a tool of fisheries management, is one of the popular instrument to control fish resources utilization. The purposes of fishing license for government are : (1) to optimalization of fish resources utilitization; (2) to maintain fish resources sustainability; and (3) to gain the economic benefit as government revenue. As part of fisheries management, fishing license affect to many aspects of fisheries as ecology, economic, technology, social, and ethic. Fishing license for large fisheries scale in Arafura Sea play an important role in Indonesian fisheries as Goverment issued 1072 fishing license or almost 25\% of total license issued for all Indonesian waters. Unfortunatelly, Arafura Sea faces many problem and issues like overfishing, IUU fishing, destructive of fish habitat and environment that threaten the sustainability of fisheries. So it's important to know the sustainability state of Arafura Sea in present to determine the best fishing license policy. The analysis of RAPFISH for sustainability of fisheries (including Leverage and Monte Carlo analysis) by major type of fisheries give some results as: (1) the fisheries of Arafura Sea is sustainable enough with score 53,86; (2) squid jigging, bottom longline, and gillnet fisheries are sustainable enough; but fish net and shrimp net are less sustainable; (3) the ecological dimension is good sustainable with score 72,43; but the ethic dimension is less sustainable with score 37,26. The leverage analysis shows the attributes which give the highest influence to each dimensions as: (1) size of fish on ecology dimension; (2) sector employment on economic dimension; (3) FAD (fish attracting devices) using and gear selectivity on technology dimension; (4) education level on social dimension; and (5) just management on ethic dimension. It's recommended for Arafura Sea fisheries development to promote the sustainability fishing gears like squid jugging, bottom longline, and gillnet fisheries.
\end{abstract}

Keywords: Fishing license, Arafura Sea, sustainability

\begin{abstract}
ABSTRAK
Perizinan penangkapan, sebagai alat pengelolaan perikanan, merupakan salah satu instrumen yang populer untuk mengendalikan pemanfaatan sumber daya ikan. Tujuan perizinan penangkapan ikan bagi pemerintah adalah: (1) untuk optimalisasi keberlanjutan sumberdaya ikan, (2) untuk mempertahankan keberlanjutan sumber daya ikan, dan (3) untuk mendapatkan manfaat ekonomi sebagai pendapatan pemerintah. Sebagai bagian dari manajemen perikanan, perizinan penangkapan mempengaruhi banyak aspek perikanan sebagai ekologi, teknologi ekonomi, sosial, dan etika. Perizinan penangkapan untuk perikanan skala besar di Laut Arafura memainkan peran penting dalam perikanan Indonesia dimana Pemerintah mengeluarkan 1.072 perizinan penangkapan atau hampir 25\% dari total modal ditempatkan perizinan untuk semua perairan Indonesia. Sayangnya, Laut Arafura menghadapi banyak masalah dan isu-isu seperti penangkapan berlebih, perikanan IUU, merusak habitat ikan dan lingkungan yang mengancam keberlanjutan perikanan. Jadi penting untuk mengetahui keadaan keberlanjutan Laut Arafura di masa sekarang untuk menentukan kebijakan perizinan penangkapan terbaik. Analisis RAPFISH untuk keberlanjutan perikanan (termasuk Leverage dan analisis Monte Carlo) menurut jenis utama perikanan memberikan beberapa hasil yaitu: (1) perikanan dari Laut Arafura adalah berkelanjutan cukup dengan skor 53,86, (2) squid jigging, rawai dasar, jaring insang dan perikanan yang berkelanjutan cukup, tetapi jaring ikan dan udang kurang berkelanjutan, (3) dimensi ekologi berkelanjutan baik dengan skor 72,43, tetapi dimensi etika kurang berkelanjutan dengan skor 37,26. Analisis Leverage menunjukkan atribut yang memberikan pengaruh tertinggi untuk masing-masing dimensi sebagai: (1) ukuran ikan pada dimensi ekologi, (2) sektor pekerjaan pada dimensi ekonomi, (3) menggunakan selektivitas FAD (perangkat menarik ikan), (4) tingkat pendidikan pada dimensi sosial, dan (5) manajemen pada dimensi etika. Ini direkomendasikan untuk pengembangan perikanan Arafura Laut untuk mempromosikan alat tangkap rawai keberlanjutan seperti squid jigging, rawai dasar, dan perikanan jaring insang.
\end{abstract}

Kata kunci: Perizinan penangkapan, Laut Arafura, berkelanjutan 


\section{PENDAHULUAN}

Perizinan merupakan salah satu instrumen pengendalian pemanfaatan sumberdaya ikan sebagai bagian dari pengelolaan perikanan (fisheries management). Tujuan utama pengendalian perikanan melalui perizinan yaitu untuk optimalisasi pemanfaatan sumber daya ikan dan menjaga kelestarian sumberdaya ikan.

Disamping itu, pengelolaan perizinan oleh Pemerintah merupakan salah satu sumber penerimaan negara berupa PNBP (Penerimaan Negara Bukan Pajak).

Pengelolaan perikanan merupakan tindakan yang berdampak pada aspekaspek multidimensional seperti aspek ekologi (sumberdaya dan habitatnya), aspek ekonomi (pendapatan nelayan, penyerapan tenaga kerja, penerimaan pemerintah), aspek teknologi (kapal dan alat penangkap ikan), aspek sosial (nelayan dan masyarakat), dan aspek etika (cara dan dampak dari pengelolaan). Berdasarkan hal tersebut, maka perizinan sebagai salah satu instrumen pengelolaan mencakup pula aspek multidimensional tersebut.

Pemerintah menerbitkan izin penangkapan ikan berdasarkan kewenangannya, dimana untuk kapal perikanan berukuran > 30 GT menjadi tanggung jawab Pemerintah Pusat, dalam hal ini Ditjen Perikanan Tangkap di Kementerian Kelautan dan Perikanan (KKP). Salah satu WPP (Wilayah Pengelolaan Perikanan) yang izinnya banyak diterbitkan oleh Pemerintah (berdasarkan permohonan dari pelaku usaha perikanan) adalah WPP Laut Arafura. WPP Laut Arafura merupakan fishing ground utama khususnya bagi usaha perikanan skala besar atau industri karena daya tarik potensi sumberdaya ikan. Sekitar 25\% izin kapal ukuran > 30 GT diterbitkan untuk wilayah Laut Arafura. Saat ini, di Laut Arafura cukup banyak isu dan permasalahan pengelolaan perikanan yang terjadi antara lain : overfishing, IUU (Illegal-Unreported and Unregulated) fishing, penurunan produktivitas, serta kerusakan lingkungan dan habitat sumberdaya ikan. Permasalahan tersebut bila dibiarkan akan mengancam keberlanjutan perikanan di Laut Arafura, termasuk kelimpahan sumberdaya ikan serta usaha perikanan tangkap sebagai mata pencaharian nelayan/pelaku usaha serta sumber PNBP.

Berdasarkan hal tersebut maka penting untuk mengkaji kebijakan perizinan usaha perikanan secara multidimesional meliputi aspek-aspek ekologi, ekonomi, teknologi, sosial dan etika. Salah satu analisis multidimensional yang dapat digunakan untuk mengetahui keberlanjutan perikanan secara cepat dan mudah adalah dengan metode RAPFISH (Rapid Appraisal for Fisheries) yang telah dikembangkan oleh University of British Columbia, Kanada.

Tujuan penelitian adalah untuk :

1. Menganalisis keberlanjutan pengelolaan perizinan kapal > $30 \mathrm{GT}$ di Laut Arafura serta faktor-faktor yang mempengaruhinya.

2. Merumuskan kebijakan dalam rangka pengelolaan perizinan yang berkelanjutan di Laut Arafura.

\section{MATERI DAN METODE}

\subsection{Tempat dan Waktu Penelitian}

Penelitian dilaksanakan pada bulan Agustus 2010 dimulai dengan survei lapangan di beberapa lokasi sentra kapal perikanan ukuran > 30 GT dan pelabuhan perikanan di sekitar Laut Arafura seperti di Maluku (Ambon dan Tual), Papua (Merauke dan Kimaam) dan Papua Barat (Avona). Dilanjutkan dengan pengolahan data primer dan sekunder serta penyusunan hasil penelitian di Bogor.

\subsection{Analisis Multidimensional dengan Metofe Rapfish}

Menurut Fauzi dan Anna (2005), salah satu alternatif pendekatan sederhana yang dapat digunakan untuk evaluasi status keberlanjutan dari perikanan adalah RAPFISH, yaitu suatu teknik multi-diciplinary rapid appraisal terbaru untuk mengevaluasi comparative sustainability dari perikanan berdasarkan sejumlah besar atribut yang mudah diskoring. RAPFISH (Rapid Appraisal for Fisheries) adalah teknik terbaru yang dikembangkan oleh University of British Columbia, Kanada, yang merupakan analisis untuk mengevaluasi sustainability dari perikanan secara multidisipliner. Pada metode RAPFISH, “perikanan" dapat 
didefinisikan secara fleksibel, dalam penelitian ini didefinisikan sebagai perizinan kapal penangkap ikan berukuran > 30 GT di Laut Arafura.

RAPFISH didasarkan pada teknik ordinasi (menempatkan sesuatu pada urutan atribut yang terukur) dengan Multi-Dimensional Scaling (MDS) yaitu teknik statistik yang mencoba melakukan transformasi multidimensi ke dalam dimensi yang lebih rendah. Dimensi dalam RAPFISH menyangkut aspek keberlanjutan dari ekologi, ekonomi, teknologi, sosial, dan etik (Lampiran 1). Setiap dimensi memiliki atribut atau indikator yang terkait dengan sustainability. Skala keberlanjutan yang digunakan sebagaimana yang digunakan Syafruddin, et al (2007) yaitu : $0-25$ (buruk), $26-50$ (kurang), $51-75$ (cukup), 76 - 100 (baik).

Analisis keberlanjutan dengan teknik RAPFISH ini dimulai dengan mereview, mengidentifikasi dan mendefinisikan atribut perikanan yang digunakan. Setelah itu dilakukan penilaian (scoring) perikanan yang dianalisis. Penilaian (scoring) didasarkan pada ketentuan yang sudah ditetapkan dalam teknik RAPFISH. Data hasil scoring selanjutnya diproses dengan menggunakan fasilitas perangkat lunak (Software) RAPFISH yang dipautkan (addins) pada MS-Excel. Sesuai masukan hasil skor atribut yang tersusun dalam matriks 'RapScores' dalam bentuk lembaran kerja perangkat lunak $M S$ Excel, maka proses pengolahan data selanjutnya berlangsung dalam perangkat lunak tersebut.

Dalam perangkat lunak (Software) RAPFISH, pengolahan terjadi dalam tiap modul VBA (Visual Basic Applications) yang masing-masing terhubung pada "g77ALSCAL.dl" untuk operasi multidimensional scalling (MDS), analisis leverage (JackKnife), dan analisis Monte Carlo.

\section{a. Analisis multi-dimensional}

Analisis multi dimensional pada dasarnya adalah teknik statistik yang mencoba melakukan transformasi multidimensi ke dalam dimensi yang lebih rendah. Transformasi ini adalah untuk menentukan posisi relatif dari perikanan terhadap ordinasi good dan bad (Fauzi dan Anna, 2002). Menurut
Kavanagh \& Pitcher (2004), atributatribut menurut dimensi dari masingmasing perikanan yang diolah datanya dalam modul 'RunRap' dan 'g77ALSCAL.dll' meliputi: (1) perhitungan statistik ('CalcStats'), (2) pembakuan ('Standardize'), (3) jarak matriks ('Proximities'), (4) rotasi ('Rotate'), dan (5) koreksi posisi ('FlipNScale').

\section{b. Analisis leverage/JackKnife (Sensitivitas)}

Setelah nilai ordinasi (indeks) keberlanjutan ditemukan melalui ordinasi RAPFISH (Hasil MDS), maka analisis leverage dilakukan untuk melihat atribut apa yang paling sensitif berpengaruh dalam memberikan kontrubusi terhadap nilai indeks keberlanjutan. Selain itu, analisis ini dilakukan untuk memperhitungkan sensitivitas setiap atribut dalam menentukan ordinasi status keberlanjutan perikanan. Pengolahan datanya dilakukan secara berulang yaitu direduksi satu per satu atribut dari dimensi keberlanjutan perikanan yang ditelaah. Untuk setiap dimensi keberlanjutan perikanan, setiap reduksi satu atributnya diproses dalam 'g77ALSCAL.dll' untuk menghasilkan ordinasi status keberlanjutan, dan selanjutnya diterima sebagai masukan oleh modul 'levereging'. Dalam modul ini, pengaruh setiap reduksi atribut diperhitungkan melalui akar kuadrat nilai tengah (RMS) ordinasi status keberlanjutan perikanan mengikuti persamaan umum :

$R M S=\sqrt{\frac{1}{N} \sum_{i=1}^{N}\left(X_{\text {red }}-\bar{X}_{f i p}\right)^{2}}$

dimana :

$X_{\text {red }}=$ hasil ordinasi reduksi atribut ('Vflip-remove),

$X_{f l i p}=$ hasil ordinasi tanpa reduksi atribut ('Vflip),

$N=$ jumlah perikanan (pukat udang, pukat ikan, gillnet, rawai dasar, pancing cumi).

Keluaran dari proses pengolahan data dalam modul 'levereging' ditunjukkan dalam lembaran kerja $M S$ Excel. Dalam hal ini, hasil-hasil analisis MDS disajikan berupa ordinasi status keberlanjutan perikanan (skala 0-100) dari setiap reduksi satu atribut ('Vflip - 
remove), dan hasil-hasil ordinasi tanpa reduksi atribut ('Vflip). Sesuai persamaan (1), hasil perhitungan RMS dinyatakan besarannya sesuai hasil komputasi dari ordinasi status keberlanjutan perikanan (skala 0-100). Artinya, semakin besar nilai perubahan RMS akibat hilangnya satu atribut tertentu, maka semakin besar pula peranan atribut dalam penentuan nilai indeks keberlanjutan pada skala 0-100, atau dengan kata lain semakin sensitif atribut tersebut dalam status keberlanjutan perikanan tangkap.

\section{c. Analisis Monte Carlo}

Dalam modul 'Monte Carlo' yang terhubung dengan 'g77ALSCAL.dll', serangkaian proses simulasi berlangsung untuk menguji pengaruh dari beragam kekeliruan (ketidakpastian), baik yang berkenaan dengan scoring maupun dalam proses ordinasi status keberlanjutan perikanan. Menurut Law dan Kelton (2000), simulasi Monte Carlo yang umumnya statik, digunakan untuk memecahkan permasalahan stokastik atau deterministik tertentu. Menurut Kavanagh dan Pitcher (2004), pembangkit bilangan acak dalam analisis ini didasarkan pada sebaran normal galat angka skor dengan nilai tengah 0 dan simpangan baku $(\sigma)$ terseleksi (noise) berselang kepercayaan (confidence interval $95 \%$ dalam proporsi $20 \%$ dari selang skor setiap atribut (skor antara 'baik' dan 'buruk'). Sesuai tabel Gaussian yang menunjukkan untuk selang kepercayaan 95\% sebesar 3,92, simpangan baku tersebut diperhitungkan sebagai berikut.

$$
\sigma_{\text {nisese }}=0,20\left(\frac{\text { skor atribut 'baik' - skor atribut ' buruk' }}{3,92}\right)
$$

Selanjutnya,untuk membangkitkan peubah acak normal 'Galat" $\left(\mathrm{G}_{1}\right.$ dan $\left.\mathrm{G}_{2}\right)$ dengan nilai tengan 0 , dan $\sigma_{\text {noise }} \mathrm{di}$ gunakan metode transformasi kebalikan "Box-Muller" (Kavanagh, 2001). Langkah awalnya yaitu membentuk sepasang peubah acak bebas 'uniform' $\left(\mathrm{U}_{1}\right.$ dan $\left.\mathrm{U}_{2}\right)$ yang menyebar antara 0 dan 1 guna menentukan magnitude $(\mathrm{r})$ dan fase $(\theta)$ dengan kaidah berikut:

$r=\sqrt{\left[-2\left\{\ln \left(U_{1}\right)\right\}\right]}$ $\theta=2 \pi\left(U_{2}\right)$

Dalam hal ini, $r$ mengikuti sebaran Rayleigh dan $\theta$ tersebar 'uniform' dari 0 ke 1. Pasangan peubah acak Gaussian dengan nilai tengah 0 dan simpangan baku $\sigma$ (noise) kemudian diperhitungkan mengikuti:

$\begin{array}{ll}X, & =r \cdot \cos (\theta) \\ X_{2} & =r \cdot \sin (\theta)\end{array}$

Pada akhirnya, penyesuaian nilai tengah dan simpangan baku dari $G_{1}$ dan $G_{2}$ diselesaikan mengikuti:

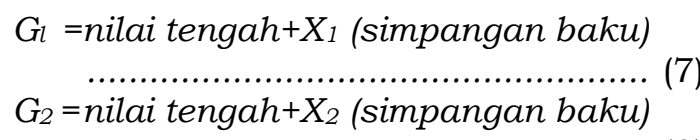

Untuk setiap atribut keberlanjutan perikanan yang ditelaah, peubah acak normal tersebut $(G)$ difungsikan sebagai 'gangguan' yang kemudian direkam pengaruhnya dalam ordinasi status keberlanjutan perikanan. Sesuai pilihan dalam perangkat lunak RAPFISH, analisis ini dijalankan sebanyak 30 kali. Hasilnya yang kemudian disajikan dalam lembaran kerja MS-Excel mencakup data dan pencaran posisi yang antara lain menunjukkan ordinasi status keberlanjutan perikanan (skala 0-100) yang dipengaruhi berulang secara acak.

\subsection{Data dan Sumber Data}

Data yang digunakan adalah data sekunder dan data primer. Data sekunder diperoleh dari literatur sedangkan data primer berdasarkan pengamatan langsung di lapangan serta wawancara dengan responden menggunakan kuesioner.

\section{HASIL DAN PEMBAHASAN}

\subsection{Keberlanjutan Perizinan}

Pengelolaan perizinan perikanan di Laut Arafura berada dalam kondisi cukup berlanjut dengan skor 53,86. Meskipun demikian, skor keberlanjutan ini mendekati kepada status kurang berlanjut sehingga diperlukan pendekatan kehati-hatian dalam pengelolaan dan pemberian izin perikanan di Laut Arafura ke depan. Bila ditinjau berdasarkan dimensi, maka dimensi ekologi memiliki skor 
keberlanjutan yang paling tinggi dengan nilai rata-rata 72,43 (cukup berlanjut), disusul oleh dimensi teknologi dengan nilai rata-rata 64,84 (cukup berlanjut), kemudian dimensi sosial dengan nilai rata-rata 51,52 (cukup berlanjut), serta dimensi ekonomi dengan nilai rata-rata 43,28 (kurang berlanjut), sedangkan terendah adalah dimensi etika dengan nilai rata-rata 37,26 (kurang berlanjut). Status dimensi ekologi yang cukup berlanjut antara lain didukung oleh kondisi perairan Arafura yang sangat subur. Sumberdaya ikan dan udang yang melimpah di perairan Arafura disebabkan ketersediaan rantai makanan yang melimpah secara alami dimana terdapat 2 (dua) bentuk basis rantai makanan yaitu basis plankton dan basis detritus (Dinas Kelautan dan Perikanan Papua, 2007). Adapun rendahnya keberlanjutan secara etika lebih disebabkan kurangnya perhatian terhadap keadilan pengelolaan perikanan yang dipengaruhi oleh sifat perikanan skala besar (komersial) umumnya yang berorientasi pada asas rasionalitas dan bisnis. Selain itu, pelaku usaha perikanan di Arafura didominasi oleh perusahaan yang berasal dari luar wilayah.

Ringkasan hasil analisis RAPFISH diuraikan pada Tabel 1dan Gambar 2.

Tabel 1. Hasil Analisis RAPFISH untuk keberlanjutan perikanan di Arafura

\begin{tabular}{|c|c|c|c|c|c|c|c|c|}
\hline \multirow{2}{*}{ Perikanan } & \multicolumn{5}{|c|}{ Skor RAPFISH } & \multirow{2}{*}{$\begin{array}{c}\text { Nilai Rata2 } \\
\text { Perikanan }\end{array}$} & \multirow{2}{*}{$\begin{array}{l}\text { Ranking } \\
\text { Perikanan }\end{array}$} & \multirow{2}{*}{$\begin{array}{c}\text { Kriteria } \\
\text { Keberlanjutan } \\
\text { Perikanan }\end{array}$} \\
\hline & Ekologi & Ekonomi & Sosial & Teknologi & Etika & & & \\
\hline - Pukat Ikan & 55,37 & 43,15 & 51,54 & 53,76 & 34,16 & 47,60 & 4 & Kurang \\
\hline - Gillnet & 91,59 & 29,42 & 49,38 & 74,96 & 40,87 & 57,24 & 3 & Cukup \\
\hline - Pukat Udang & 46,25 & 42,13 & 53,17 & 60,28 & 19,63 & 44,29 & 5 & Kurang \\
\hline $\begin{array}{l}\text { - Pancing } \\
\text { Cumi }\end{array}$ & 91,58 & 56,47 & 51,13 & 65,75 & 45,80 & 62,15 & 1 & Cukup \\
\hline $\begin{array}{l}\text { - Pancing } \\
\text { Rawai Dasar }\end{array}$ & 77,35 & 45,24 & 52,39 & 69,42 & 45,80 & 58,04 & 2 & Cukup \\
\hline $\begin{array}{l}\text { Nilai Rata2 } \\
\text { Dimensi }\end{array}$ & 72,43 & 43,28 & 51,52 & 64,84 & 37,26 & 53,86 & - & - \\
\hline $\begin{array}{l}\text { Ranking } \\
\text { (Dimensi) }\end{array}$ & 1 & 4 & 3 & 2 & 5 & - & - & - \\
\hline $\begin{array}{l}\text { Kriteria } \\
\text { Keberlanjutan } \\
\text { (Dimensi) }\end{array}$ & Cukup & Kurang & Cukup & Cukup & Kurang & - & - & - \\
\hline
\end{tabular}

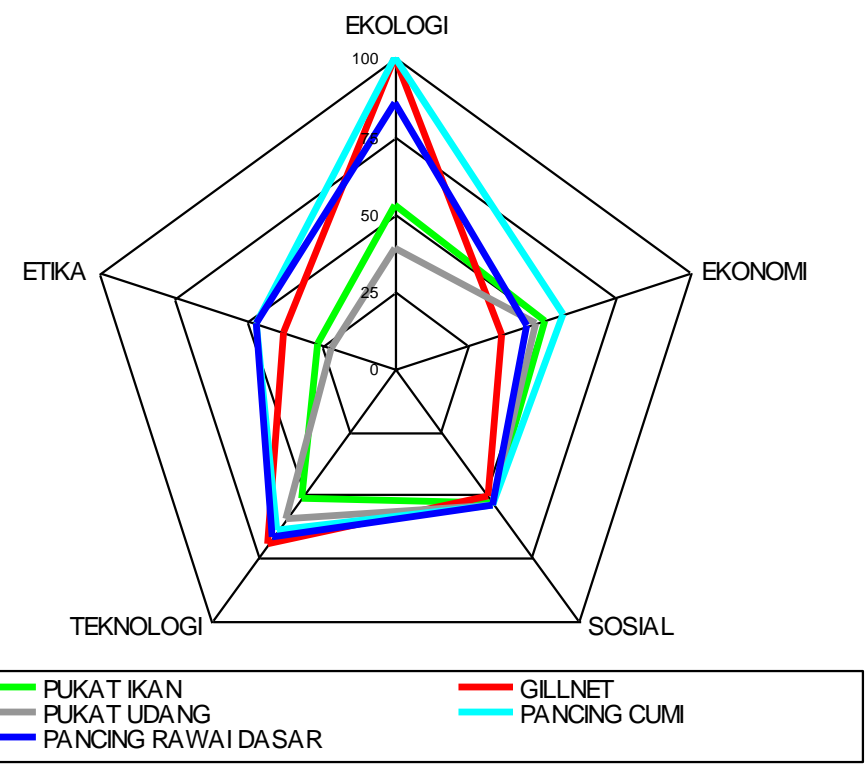

Gambar 1. Diagram layang-layang hasil analisis RAPFISH berdasarkan dimensi 


\subsection{Analisis Atribut}

Hasil

analisis

leverage menunjukkan bahwa atribut yang paling berpengaruh pada masing-masing dimensi adalah: (1) ukuran ikan tangkapan pada dimensi ekologi; (2) ketenagakerjaan pada dimensi ekonomi; (3) penggunaan FAD (fish attracting devices) dan selektivitas alat pada dimensi teknologi; (4) tingkat pendidikan pada dimensi sosial; dan (5) keadilan dalam hal pengelolaan pada dimensi etika. Ukuran ikan yang tertangkap (perubahannya) dapat menggambarkan secara jelas kondisi keberlanjutan ekologi perairan Arafura. Sementara itu, secara ekonomi jelas bahwa usaha perikanan tangkap memberikan sumbangan paling nyata dalam bentuk penyerapan tenaga kerja. Semakin banyak jumlah tenaga kerja yang terserap maka akan semakin besar kontribusi suatu perikanan dari sisi ekonomi. Penggunaan FAD (fish attracting devices) dan selektivitas alat penangkap ikan merupakan bagian penting dari dimensi keberlanjutan teknologi karena berhubungan langsung dengan kinerja usaha perikanan tangkap yang dilakukan. Dengan kata lain bahwa performa keberlanjutan perikanan dari aspek teknologi sangat ditentukan dari penggunaan FAD dan selektivitas alat penangkap ikan. Tingkat pendidikan dan pengaruh nelayan terhadap perikanan merupakan 2 (dua) atribut paling penting pada dimensi sosial. Tingkat pendidikan pelaku usaha perikanan akan mempengaruhi seluruh atribut sosial lainnya, contohnya adalah pendidikan yang tinggi akan mempengaruhi pemahaman terhadap peraturan, konflik, lingkungan, dan lain-lain. Sementara itu, pengaruh nelayan terhadap perikanan juga sangat besar berpengaruh mengingat kedudukan nelayan sebagai pelaku langsung (aktor utama) usaha perikanan sekaligus posisinya sebagai bagian dari masyarakat. Secara etika, usaha perikanan akan memiliki nilai yang tinggi bila memperhatikan dan melibatkan aspek masyarakat lokal dalam kegiatannya. Keadilan dalam hal pengelolaan akan mempengaruhi tingkat penerimaan atau penolakan masyarakat terhadap usaha perikanan yang dilakukan.

Atribut yang paling sedikit pengaruhnya pada masing-masing dimensi adalah: (1) jumlah spesies tangkapan pada dimensi ekologi; (2) subsidi dan kontribusi PNBP pada dimensi ekonomi; (3) sosialisasi penangkapan pada dimensi sosial; (4) penanganan di atas kapal pada dimensi teknologi; dan (5) mitigasi-deplesi ekosistem/habitat pada dimensi etika. Secara ekologi, jumlah spesies tangkapan di Arafura tidak terlalu berpengaruh untuk setiap perikanan mengingat Laut Arafura sebagai perairan tropis yang kaya akan spesies serta penggunaan alat penangkap ikan yang tidak bersifat khas untuk setiap target ikan yang ditangkap. Keberadaan subsidi tidak memberikan pengaruh berarti bagi perikanan skala besar (komersial) karena secara ekonomi mereka memiliki modal yang kuat. Hal ini diperkuat oleh hasil survey responden yang menunjukkan bahwa usaha penangkapan ikan skala besar tetap eksis walau tanpa disubsidi oleh Pemerintah. Sementara itu, kontribusi PNBP yang ditarik dari usaha perikanan skala besar ternyata juga kecil pengaruhnya yang berarti tarif yang ditetapkan oleh Pemerintah masih kondusif bagi usaha perikanan tangkap di Arafura. Sosialisasi penangkapan tidak berpengaruh besar terhadap aspek sosial karena pelaku usaha umumnya sudah mengetahui aturan di bidang penangkapan ikan yang setiap tahunnya dilakukan oleh Pemerintah dengan peserta sosialisasi yang cenderung tidak variatif. Penanganan di atas kapal belum sepenuhnya disadari oleh pelaku usaha perikanan sehingga pengaruhnya secara teknologi tidaklah besar. Penanganan ikan di atas kapal merupakan bagian penting dari mata rantai produksi perikanan yang baik dan bermutu tinggi, khususnya bagi produk perikanan yang akan diekspor. Demikian pula mitigasideplesi ekosistem/habitat perairan belum diperhatikan oleh pelaku usaha penangkapan ikan sehingga pengaruhnya secara etika adalah rendah. Usaha perikanan yang dilakukan masih berorientasi kepada maksimalisasi keuntungan yang akhirnya cenderung mengabaikan kondisi lingkungan dan sumberdaya ikan. 


\subsection{Kebijakan Teknis Operasional Perizinan}

Berdasarkan hasil analisis atribut dapat dirumuskan kebijakan teknis operasional perizinan usaha perikanan tangkap dalam rangka keberlanjutan, sebagai berikut :

1. Pemberlakuan management measures untuk mengendalikan ukuran ikan yang tertangkap.

2. Peningkatkan serapan tenaga kerja lokal

3. Peningkatan selektivitas alat penangkap ikan

4. Peningkatan pendidikan dan latihan SDM perikanan, termasuk nelayan dan pelaku usaha perikanan.

5. Peningkatan keadilan kegiatan perikanan

Sedangkan kebijakan teknis yang belum memberikan dampak saat ini sehingga perlu ditinjau kembali atau disempurnakan antara lain :

1. Kebijakan menyangkut komposisi jenis ikan tertangkap

2. Penerapan subsidi untuk usaha perikanan tangkap

3. Pengenaan tarif dalam rangka PNBP

4. Sosialisasi perizinan usaha penangkapan ikan

5. Penanganan ikan di atas kapal perikanan

6. Kebijakan terkait pencegahan kerusakan habitat ikan/lingkungan

\section{KESIMPULAN DAN SARAN}

\subsection{Kesimpulan}

Status perikanan di Arafura dalam keadaan cukup berlanjut dengan skor 53,86. Berdasarkan dimensi/aspek, ada 3 (tiga) dimensi dalam status cukup beranjut yaitu ekologi, teknologi, dan sosial; sedangkan aspek ekonomi dan etik dalam status kurang berlanjut.

Atribut yang paling berpengaruh pada masing-masing dimensi adalah: (1) ukuran ikan tangkapan pada dimensi ekologi; (2) ketenagakerjaan pada dimensi ekonomi; (3) penggunaan FAD (fish attracting devices) dan selektivitas alat pada dimensi teknologi; (4) tingkat pendidikan pada dimensi sosial; dan (5) keadilan dalam hal pengelolaan pada dimensi etika. Atribut yang paling sedikit pengaruhnya pada masingmasing dimensi adalah: (1) jumlah spesies tangkapan pada dimensi ekologi; (2) subsidi dan kontribusi PNBP pada dimensi ekonomi; (3) sosialisasi penangkapan pada dimensi sosial; (4) penanganan di atas kapal pada dimensi teknologi; dan (5) mitigasi-deplesi ekosistem/habitat pada dimensi etika.

Untuk meningkatkan keberlanjutan perikanan di Arafura dapat digunakan intervensi atau kebijakan teknis operasional perizinan antara lain :

1. Pengaturan perikanan (management measures) untuk mendukung perbaikan kondisi ekologi perikanan.

2. Peningkatan penyerapan tenaga kerja, khususnya tenaga kerja lokal.

3. Peningkatan selektivitas alat penangkap ikan dan penggunaan FAD.

4. Peningkatan kualitas SDM (pengetahuan dan keterampilan) pelaku usaha perikanan, termasuk nelayan.

5. Peningkatan keadilan dan partisipasi masyarakat/ nelayan dalam usaha perikanan.

Adapun kebijakan yang dapat ditinjau kembali atau disempurnakan karena belum memberikan dampak yaitu: (1) terkait komposisi jenis ikan; (2) pengenaan subsidi; (3) pengenaan tarif pungutan; (4) sosialisasi perizinan; (5) penanganan di atas kapal; dan (6) kepedulian lingkungan/habitat ikan.

\subsection{Saran}

Perlu ditingkatkan kebijakan yang memberikan dampak besar, sedangkan untuk yang kurang memberikan dampak agar disempurnakan atau bahkan dihilangkan.

\section{DAFTAR PUSTAKA}

Badan Riset Kelautan dan Perikanan. 2007. Wilayah Pengelolaan Perikanan, Status Perikanan Menurut Wilayah. Informasi Dasar pemanfaatan Berkelanjutan. Pusat Riset Perikanan Tangkap. 47 hal.

Badan Riset Kelautan dan Perikanan. 2004. Penelitian Bio-Ekologi Sumberdaya Perikanan (Ikan Demersal, Pelagis Besar dan Pelagis Kecil) di Perairan Laut Arafura, Laut Banda dan Sekitarnya, dalam Jurnal Bagian I Iptek Kelautan dan Perikanan Masa Kini.

Ditjen Perikanan Tangkap. 2007. Statistik Perikanan Tangkap di Laut Menurut WPP, 2001 - 2005. 
Fauzi, A.S. dan Anna S., 2005. Pemodelan Sumberdaya Perikanan dan Kelautan untuk Analisis Kebijakan. Penerbit PT. Gramedia Pustaka Utama. Jakarta. 2005.

Fauzi A dan Anna S. 2002. Evaluasi Status Keberlanjutan Pembangunan Perikanan : Aplikasi Pendekatan Rapfish (Studi Kasus Perairan DKI Jakarta). Jurnal Pesisir dan Lautan Vol. 4 (3). pp: 43-55.

Kavanagh, P. and Pitcher, T.J., 2004. Implementing Microsoft Excel Software for RAPFISH : A Technique for The Rapid Appraisal of Fisheries Status. The Fisheries Centre, University of British Columbia, 2259 Lower Mall Vancouver, Canada, V6T IZ4.

Law AM. and Kelton WD. 2000. Simulation Modeling and Analysis. Boston: McGraw-Hill (Third Edition). 760 p.
Majalah Demersal edisi Juli 2007. Opini Bahari Dinas Perikanan dan Kelautan Provinsi Papua.

Nikijuluw VPH. 2008. Blue Water Crime: Dimensi Sosial Ekonomi Perikanan Ilegal. Penerbit Cidesindo. Jakarta. 196 hal.

Pitcher, T.J. and Preikshot D., 2000. A Rapid Appraisal Technique to Evaluate The Sustainability Status of Fisheries. Fisheries Center. University of British Columbia, 2204 Main Mall. Vancouver. Canada. V7R 2L7.

Syafruddin, Surjono H.S., Yayuk F.B., dan Rita Nurmalina. Strategi Pengelolaan dan Analisis Status Keberlanjutan Ketahanan Pangan di Kabupaten Halmahera Tengah. Jurnal Pengkajian dan Pengembangan Teknologi Pertanian Vol. 10, No. 1, Juni 2007: 30-38. 
Lampiran 1. Atribut dan kriteria (dimodifikasi dari Pitcher and Preikshot, 2000)

\begin{tabular}{|c|c|c|c|}
\hline Dimensi & No & Atribut & Kriteria \\
\hline \multirow[t]{8}{*}{ Ekologi } & 1 & Status eksploitasi & Under exploited s/d kolaps \\
\hline & 2 & Keragaman rekrutmen & Nilai koefisien keragaman \\
\hline & 3 & Jarak migrasi & Jumlah yurisdiksi terkait daur hidup \\
\hline & 4 & Tingkatan kolaps & Pengurangan lokasi area tangkap \\
\hline & 5 & Ukuran ikan tangkapan & Perubahan selama 5 tahun terakhir \\
\hline & 6 & Tangkapan pra-maturity & Proporsi terhadap hasil tangkapan \\
\hline & 7 & Discarded dan by catch & Proporsi terhadap target hasil tangkapan \\
\hline & 8 & Spesies tangkapan & Jumlah spesies termasuk by-catch \\
\hline \multirow[t]{10}{*}{ Ekonomi } & 9 & Kontribusi PNBP & Rendah s/d tinggi \\
\hline & 10 & Gaji atau upah rata-rata & $\begin{array}{l}\text { Perbandingan gaji nelayan terhadap lain } \\
\text { pekerja }\end{array}$ \\
\hline & 11 & Pembatasan masuk & Open access s/d banyak \\
\hline & 12 & Sifat pemasaran & Kuota s/d 'share' \\
\hline & 13 & Pendapatan lain & $\begin{array}{l}\text { Penangkapan dilakukan sambilan s/d full } \\
\text { time }\end{array}$ \\
\hline & 14 & Ketenagakerjaan & $\begin{array}{l}\begin{array}{l}\text { Proporsi aktivitas ini } \\
\text { perikanan }\end{array} \\
\end{array}$ \\
\hline & 15 & Kepemilikan & $\begin{array}{l}\text { Profit perikanan terutama untuk lokal s/d } \\
\text { asing }\end{array}$ \\
\hline & 16 & Pasar utama & Lokal s/d asing \\
\hline & 17 & Subsidi & Tidak ada s/d penuh \\
\hline & 18 & Konsumsi BBM & Rendah s/d tinggi \\
\hline \multirow[t]{10}{*}{ Sosial } & 19 & Sosialisasi penangkapan & Target sosialisasi \\
\hline & 20 & Pendatang baru & Proporsi selama 10 tahun terakhir \\
\hline & 21 & Sektor penangkapan & Proporsi RTP nelayan dalam komunitas \\
\hline & 22 & Pengetahuan lingkungan & Tidak tahu s/d banyak mengetahui \\
\hline & 23 & Tingkat pendidikan & Terhadap rata-rata penduduk \\
\hline & 24 & Status konflik & $\begin{array}{lll}\text { Keberadaan konflik } & \text { dengan } \\
\text { perikanan/sektor lain } & \\
\end{array}$ \\
\hline & 25 & Pengaruh nelayan & Terhadap regulasi aktual \\
\hline & 26 & $\begin{array}{l}\text { Keterlibatan tenaga kerja } \\
\text { local }\end{array}$ & Rendah s/d tinggi \\
\hline & 27 & Pendapatan penangkapan & $\begin{array}{l}\text { Proporsi terhadap total pendapatan } \\
\text { keluarga }\end{array}$ \\
\hline & 28 & Partisipasi keluarga & $\begin{array}{l}\text { Adanya anggota keluarga menjual atau } \\
\text { memproses hasil tangkapan }\end{array}$ \\
\hline \multirow[t]{9}{*}{ Teknologi } & 29 & Lama trip & Rata-rata hari setiap trip \\
\hline & 30 & $\begin{array}{l}\text { Tempat pendaratan } \\
\text { (pelabuhan) }\end{array}$ & Penyebarannya \\
\hline & 31 & Pengolahan pra-jual (UPI) & Keberadaan pengolahan pra-jual \\
\hline & 32 & Penanganan di kapal & Teknologi yang digunakan \\
\hline & 33 & Selektivitas alat tangkap & $\begin{array}{llll}\begin{array}{l}\text { Tingkat selektivitas } \\
\text { peningkatannya }\end{array} & \text { dan } & \text { upaya } \\
\end{array}$ \\
\hline & 34 & Penggunaan FADs & Ada tidaknya FADs \\
\hline & 35 & Ukuran kapal & Rata-rata panjang kapal \\
\hline & 36 & Perubahan daya tangkap & Perubahan selama 5 tahun terakhir \\
\hline & 37 & Efek samping alat tangkap & Tidak ada efek s/d efek merusak \\
\hline \multirow[t]{8}{*}{ Etika } & 38 & $\begin{array}{l}\text { Keterpautan historis atau } \\
\text { geografis }\end{array}$ & Kedekatan dan keterkaitan \\
\hline & 39 & Pilihan perikanan & Keberadaan pilihan kegiatan perikanan \\
\hline & 40 & Kesetaraan kesempatan & Pertimbangan basis tradisi atau historis \\
\hline & 41 & Keadilan dalam pengelolaan & $\begin{array}{l}\text { Pola pengelolaan dengan keterlibatan } \\
\text { masyarakat }\end{array}$ \\
\hline & 42 & Mitigasi-Destruksi habitat & Tingkat mitigasi dan destruksi \\
\hline & 43 & Mitigasi-deplesi ekosistem & Tingkat mitigasi dan deplesi \\
\hline & 44 & $\begin{array}{l}\text { Penangkapan } \\
\text { melanggar aturan }\end{array}$ & Keberadaan pelaggaran kegiatan perikanan \\
\hline & 45 & Buangan dan limbah & Keberadan buangan/limbah \\
\hline
\end{tabular}


